\title{
AVALIAÇÃO DO NÍVEL DE RUÍDO EM COLHEDORAS COMBINADAS ${ }^{1}$
}

\section{ROUVERSON P. DA SILVA ${ }^{2}$, GUSTAVO FONTANA ${ }^{3}$, AFONSO LOPES ${ }^{2}$, CARLOS E. A. FURLANI ${ }^{2}$}

RESUMO: O presente trabalho teve o objetivo de determinar os níveis de pressão sonora nas cabines de colhedoras combinadas, por meio do uso de um medidor de nível de pressão sonora. Foram avaliadas as colhedoras New Holland TC-57, SLC 6200 e Massey Ferguson 3640, sendo determinado o nível de ruído na cabine do operador. O delineamento adotado foi o inteiramente casualizado, com 12 tratamentos e três repetições. Os resultados obtidos evidenciam que todas as colhedoras estudadas apresentaram ruído acima do nível máximo estabelecido pelas normas técnicas.

PALAVRAS-CHAVE: ruído, colhedoras de grãos, cabines.

\section{EVALUATION OF NOISE LEVEL OF COMBINE HARVESTERS}

SUMMARY: The present work aimed to study the noise levels from some combine harvesters. The following harvesters were evaluated: "NH TC-57", "SLC 6200" and "MF 3640", according to the noise level from the operator position, within a randomized complete block design with twelve treatments and three repetitions. All the studied harvesters provided noise levels above the maximum established by technical norms.

KEYWORDS: noise, combine harvesters, cab.

\section{INTRODUÇÃO}

O conceito de ruído é associado a uma intensidade do som, enquanto o som é definido como sendo a variação da pressão atmosférica dentro dos limites de amplitude e bandas de frequiências aos quais o ouvido humano responde (GERGES, 1992). ASETE (1983) define o ruído como sendo um som desagradável ou indesejado, propagado em meio elástico como ar, água e sólidos. Outra definição para ruído é dada pela norma ISO (INTERNATIONAL..., 1975), que o classifica como uma classe de sons, geralmente de natureza aleatória, em que não existe definição clara da freqüência de seus componentes. De acordo com GRANDJEAN (1982), o ruído é um complexo de sons que causam sensação de desconforto e está presente de forma contínua, na vida diária dos seres humanos.

HILBERT (1998) afirma que, para a diminuição do nível de ruído com a conseqüente melhora do ambiente de trabalho, é necessário entender os princípios básicos de sua geração, transmissão e recepção. O reconhecimento do som é feito no ouvido pela mudança de pressão do ar ambiente. Do ponto de vista fisiológico e da ergonomia do posto de trabalho do operador, são duas as características de interesse do ruído emitido por tratores: altura e intensidade (MIALHE, 1996). O ruído é medido em uma escala logarítmica denominada decibel (dB) (IIDA, 1990; PMAC, 1994), existindo duas medidas fundamentais de ruído: uma que se refere ao ruído transmitido ao ambiente e outra que estabelece o ruído que afeta o operador. Os limites são estabelecidos de acordo com as medidas realizadas a 7,5 m de distância da fonte sonora, admitindo-se um nível máximo de ruído de $85 \mathrm{dBA}$, independentemente da condição de movimento (CAÑAVATE, 1982). O nível de ruído em tratores agrícolas é avaliado

\footnotetext{
${ }^{1}$ Trabalho apresentado no XXXI Congresso Brasileiro de Engenharia Agrícola.

2 Prof. Dr., Departamento de Engenharia Rural, Faculdade de Ciências Agrárias e Veterinárias, UNESP, Jaboticabal - SP, Fone: (0XX16) 3209.2637, e-mail: rouverson@fcav.unesp.br

${ }^{3}$ Engenheiro Agrícola, mestrando em Máquinas Agrícolas pela ESALQ/USP, e-mail: gfontana@esalq.usp.br

Recebido pelo Conselho Editorial em: 15-10-2002

Aprovado pelo Conselho Editorial em: 5-5-2004
} 
segundo normas internacionais e nacionais que, de acordo com HILBERT (1998), são extensivas às máquinas autopropelidas, como as colhedoras combinadas. Os critérios para a medição do ruído e estimativa do risco para o trabalhador foram inicialmente estabelecidos pela Norma ISO 1999 (INTERNATIONAL ..., 1975). Posteriormente, uma revisão dessa Norma (INTERNATIONAL ..., 1982) estabeleceu limites mais severos para os níveis de ruído que ocorrem no posto de trabalho.

No Brasil, a Associação Brasileira de Normas Técnicas (ABNT) possui algumas normas sobre medições de ruído em máquinas agrícolas, sendo as principais a NBR-9999 (ABNT, 1987) e a NBR 10400 (ABNT, 1988). A Norma NB 95 (ABNT, 1987) estabelece os níveis máximos de ruído que permitem o mínimo de conforto aos ocupantes de um ambiente. $\mathrm{O}$ máximo estabelecido é de $85 \mathrm{~dB}$ (A), e acima desse limite o ruído, além de perturbar as atividades humanas, pode causar sérios danos à audição. Para o ruído contínuo ou intermitente, a NR-15 (Norma Regulamentadora), aprovada pela Portaria $\mathrm{n}^{\circ} 3214$ de 8 de junho de 1978 (MINISTÉRIO DO TRABALHO..., 2003), estabelece que, para indivíduos que não estejam adequadamente protegidos, não é permitida a exposição a níveis de ruído acima de $115 \mathrm{~dB}(\mathrm{~A})$.

Um dos primeiros estudos de caracterização das fontes de ruído no Brasil foi apresentado por FERNANDES et al. (1991) que, medindo o nível de ruído nos ouvidos direito e esquerdo do tratorista, não encontrou diferenças significativas, concluindo que, de maneira geral, os tratores apresentavam níveis de ruído muito acima dos limites de conforto estabelecidos pela Norma NB-95, como também acima do limite de $85 \mathrm{~dB}(\mathrm{~A})$ para 8 h de exposição diária, estabelecido pela NR-15 (MINISTÉRIO DO TRABALHO..., 2003).

CAMPANA (1984), ao estudar o nível de ruído em tratores com cabines, concluiu que 94,5\% dos tratores avaliados apresentaram nível de ruído igual ou superior a $85 \mathrm{~dB}$ (A). Resultados semelhantes também foram obtidos por ZAMBERLAN et al. (1988), que chegaram à conclusão de que, tanto em ensaios padronizados quanto em condições reais de trabalho, nenhum dos tratores estudados apresentou condições aceitáveis de trabalho aos tratoristas.

O presente trabalho teve por objetivo analisar três modelos de colhedoras combinadas empregadas na colheita de milho, para avaliar o nível de ruído no posto do operador das colhedoras e confrontar os resultados obtidos com as normas específicas dessa área.

\section{MATERIAL E MÉTODOS}

Para a realização dos ensaios, foram selecionadas três propriedades produtoras de milho, localizadas na região de Uberaba - MG, cujas localizações são apresentadas na Tabela 1.

Foram utilizadas neste trabalho as colhedoras New Holland TC-57, SLC 6200 e Massey Ferguson 3640, equipadas com plataforma para milho, cujas características são apresentadas na Tabela 2. As máquinas foram selecionadas de acordo com o perfil da mecanização agrícola regional, determinado por SILVA et al. (1998).

TABELA 1. Localização da área de estudo.

\begin{tabular}{lcccc}
\hline \multicolumn{1}{c}{ Propriedade } & Área (ha) & Município & Latitude & Longitude \\
\hline Fazenda Getúlio Vargas & 120 & Uberaba & $19^{\circ} 08^{\prime} 00^{\prime \prime} \mathrm{S}$ & $47^{\circ} 37^{\prime} 00^{\prime} \mathrm{W}$ \\
Fazenda Primavera & 140 & Sacramento & $19^{\circ} 32^{\prime} 00^{\prime} \mathrm{S}$ & $4^{\circ} 02^{\prime} 00^{\prime} \mathrm{W}$ \\
Fazenda Santana & 200 & Nova Ponte & $18^{\circ} 55^{\prime} 00^{\prime} \mathrm{S}$ & $47^{\circ} 33^{\prime} 00^{\prime} \mathrm{W}$ \\
\hline
\end{tabular}


TABELA 2. Características das colhedoras avaliadas.

\begin{tabular}{lccc}
\hline \multicolumn{1}{c}{ Características } & NH TC-57 & SLC 6200 & MF 3640 \\
\hline Potência kW - (cv) & $125-(170)$ & $110-(148)$ & $110-(148)$ \\
Número de cilindros & 6 (turbo) & 6 (turbo) & 6 (turbo) \\
Tanque graneleiro $\left(\mathrm{m}^{3}\right)$ & 5,00 & 3,43 & 3,40 \\
Massa $(\mathrm{t})$ & 9,46 & 8,57 & 6,17 \\
Cabine & Sim & Não & Não \\
Idade (horas) & 1835 & 3400 & $1.185^{*}$ \\
\hline
\end{tabular}

* A colhedora MF-3640, apesar de apresentar idade defasada, possui poucas horas trabalhadas, pois realiza a colheita de grãos apenas em experimentos desenvolvidos em Instituições de Ensino e Pesquisa de Uberaba.

O nível de ruído na cabine do operador foi determinado por meio de delineamento inteiramente casualizado, com 12 tratamentos e três repetições, conforme Tabela 3. Para a medição do nível de ruído, utilizou-se um medidor de nível de pressão sonora da marca Extech Instruments ${ }^{\circledR}$, modelo 407706, com escalas de baixa e alta intensidade de 40 a 80 e 80 a $120 \mathrm{~dB}$, respectivamente. O medidor de nível de pressão sonora foi calibrado com um áudio calibrador, marca Extech Instruments ${ }^{\circledR}$, modelo 407744 (nível sonoro: $94 \mathrm{~dB}$ a $1000 \mathrm{~Hz}\left(23^{\circ}\right)$; distorção: menor que 5\%).

Nas medições de ruído, utilizou-se o circuito de compensação "A" do medidor de pressão sonora. Portanto, os valores medidos em $\mathrm{dB}(\mathrm{A})$ representam o número de pressão sonora equalizado de acordo com a curva "A" do aparelho, padronizada internacionalmente - Normas IEC 651 e EB 386, citadas pela NBR-9999 (ABNT, 1987).

TABELA 3. Delineamento experimental para a determinação do nível de ruído.

\begin{tabular}{cl}
\hline Tratamento & \multicolumn{1}{c}{ Descrição } \\
\hline T1 & Colhedora NH TC-57 em movimento, sem a presença de trator do lado. \\
T2 & Colhedora MF-3640 em movimento, sem a presença de trator do lado. \\
T3 & Colhedora SLC-6200 em movimento, sem a presença de trator do lado. \\
T4 & Colhedoras NH TC-57 em movimento, com a presença de trator do lado. \\
T5 & Colhedoras MF-3640 em movimento, com a presença de trator do lado. \\
T6 & Colhedoras SLC-6200 em movimento, com a presença de trator do lado. \\
T7 & Colhedoras NH TC-57 descarregando com trator Ford 7630 ao lado, ambos ligados e \\
& parados. \\
T8 & Colhedoras MF-3640 descarregando com trator Ford 7630 ao lado, ambos ligados e \\
& parados. \\
T9 & Colhedoras SLC-6200 descarregando com trator Ford 7630 ao lado, ambos ligados e \\
T10 & Colhedora NH TC-57 em movimento, com fluxo de ar-condicionado no mínimo. \\
T11 & Colhedora NH TC-57 em movimento, com fluxo de ar-condicionado na posição média. \\
T12 & Colhedora NH TC-57 em movimento, com fluxo de ar-condicionado no máximo. \\
\hline
\end{tabular}

Para realizar as medições, colocou-se o medidor de nível de pressão sonora ao ouvido do tratorista, entre $79 \mathrm{~cm}$ acima, $15 \mathrm{~cm}$ a frente e $20 \mathrm{~cm}$ lateralmente em relação ao ponto de referência do assento - PRA, de acordo com a norma NBR 9405 (ABNT, 1985), onde se realizaram cinco leituras com a máquina parada, com intervalos de $5 \mathrm{~s}$ entre as leituras. Para os conjuntos motomecanizados em operação, foi adotado o mesmo procedimento, sendo tomadas 20 leituras, também com intervalos de $5 \mathrm{~s}$ entre as mesmas. Em todas as amostragens realizadas, foram aguardados três minutos antes da medição, tempo esse necessário para que a colhedora entrasse em regime de trabalho. Para obter uma padronização dos tratamentos, todas as colhedoras operaram em segunda marcha, a $2.200 \mathrm{rpm}$, 
situação que expressa as condições reais de trabalho para a colheita de milho nas propriedades selecionadas.

Para a colhedora New Holland TC-57, que possui cabine fechada, foram coletadas amostras com o ar-condicionado regulado nas intensidades mínima, média e máxima (tratamentos T10, T11 e T12) para verificar possíveis alterações na amostragem do nível de ruído. Os demais tratamentos com a colhedora New Holland TC-57 (tratamentos T1, T4 e T7) foram realizados com o fluxo de ar em sua intensidade média, apontada pelo operador como sendo a mais utilizada em regime normal de trabalho.

Os tratamentos foram, então, organizados em função das seguintes condições:

- Condição 1: colhedoras em movimento;

- Condição 2: colhedoras descarregando com trator Ford 7630 ao lado, ambos ligados e parados;

- Condição 3: colhedora New Holland TC-57 em movimento com mudanças na intensidade do fluxo de ar-condicionado.

Os resultados encontrados foram comparados com os limites de tolerância estabelecidos pela NR-15 (MINISTÉRIO DO TRABALHO ..., 2003), conforme apresentado na Tabela 4.

Para respaldar as discussões, são apresentadas as análises de variância para os valores médios do nível de ruído obtidos durante a colheita de milho na safra 2000-2001, realizada no mês de abril, nas propriedades selecionadas.

Os resultados analisados estatisticamente encontram-se acompanhados das análises de variância do teste $\mathrm{F}$ e do teste de Tukey. As médias seguidas de mesma letra nas colunas indicam que os valores apresentados não diferiram entre si, a $5 \%$ de probabilidade.

TABELA 4. Limites de tolerância para ruído contínuo ou intermitente.

\begin{tabular}{cc}
\hline Ruído $[\mathrm{dB}(\mathrm{A})]$ & Máxima Exposição Diária Permissível \\
\hline 85 & 8 horas \\
86 & 7 horas \\
87 & 6 horas \\
88 & 5 horas \\
89 & 4 horas e 30 minutos \\
90 & 4 horas \\
91 & 3 horas e 30 minutos \\
92 & 3 horas \\
93 & 2 horas e 40 minutos \\
94 & 2 horas e 15 minutos \\
95 & 2 horas \\
96 & 1 hora e 45 minutos \\
98 & 1 hora e 15 minutos \\
100 & 1 hora \\
102 & 45 minutos \\
104 & 35 minutos \\
105 & 30 minutos \\
106 & 25 minutos \\
108 & 20 minutos \\
110 & 15 minutos \\
112 & 10 minutos \\
114 & 8 minutos \\
115 & 7 minutos \\
\hline
\end{tabular}




\section{RESULTADOS E DISCUSSÃO}

\section{Ruído das colhedoras TC 57, SLC 6200 e MF 3640}

Quando comparados os modelos de colhedoras em movimento, observa-se que os valores médios do nível de ruído diferiram entre si, a 5\% de probabilidade (Tabela 5). O maior nível de ruído foi encontrado para a colhedora Massey Ferguson 3640 com trator ao lado (tratamento T5) que, dentre as colhedoras analisadas, é a mais antiga e a de menor potência. Entre os seis tratamentos, a colhedora mais nova e de maior potência (NH TC-57) foi a que apresentou nível de ruído significativamente inferior aos demais. A presença de um trator ao lado da colhedora provocou alteração no nível de ruído para as colhedoras NH TC-57 (T1 e T4) e MF-3640 (T2 e T5). Para a colhedora SLC-6200 (T3 e T6), não foram encontradas diferenças significativas para os tratamentos com e sem a presença de trator ao lado durante a descarga do tanque graneleiro. Para a situação de colheita e descarga simultâneas, com tratores acompanhando as colhedoras (T4, T5 e T6), observa-se que a colhedora MF 3640 apresentou significativamente o maior nível de ruído, enquanto as colhedoras NH TC-57 e SLC-6200 apresentaram níveis de ruído estatisticamente iguais (Tabela 5).

TABELA 5. Valores médios do nível de ruído para as colhedoras em movimento.

\begin{tabular}{cc}
\hline Tratamento & Ruído [dB (A)] \\
\hline T1 & $95,50 \mathrm{a}$ \\
T2 & $98,80 \mathrm{~b}$ \\
T3 & $99,00 \mathrm{~b}$ \\
T4 & $99,00 \mathrm{~b}$ \\
T5 & $101,00 \mathrm{c}$ \\
T6 & $98,80 \mathrm{~b}$ \\
\hline F calculado: 34,01 & C.V. $(\%): 0,534$
\end{tabular}

Médias seguidas de mesma letra nas colunas indicam que os valores apresentados não diferiram entre si, a 5\% de probabilidade.

Analisando os tratamentos em que as colhedoras estavam descarregando ao lado de um trator, ambos ligados e parados, observa-se que não houve diferença significativa para as colhedoras analisadas (Tabela 6). Os resultados são semelhantes, pois ambas as máquinas agrícolas permaneceram em funcionamento e paradas, com o sistema de trilha da colhedora permanecendo desligado. Dessa forma, foi analisado apenas o nível de ruído devido ao descarregamento dos grãos e ao funcionamento do motor (Tabela 6).

TABELA 6. Valores médios do nível de ruído para as colhedoras descarregando com trator Ford 7630 ao lado, ambos ligados e parados.

\begin{tabular}{cc}
\hline Tratamento & Ruído [dB (A)] \\
\hline T7 & $99,000 \mathrm{a}$ \\
T8 & $95,333 \mathrm{a}$ \\
T9 & $95,333 \mathrm{a}$ \\
\hline
\end{tabular}

F. calculado: 3,184

C.V. $(\%): 2,128$

Médias seguidas de mesma letra nas colunas indicam que os valores apresentados não diferiram entre si, a $5 \%$ de probabilidade.

\section{Ruído da colhedora TC 57}

A análise estatística permite avaliar que os tratamentos com o ar-condicionado regulado nas intensidades de mínimo, médio e máximo não diferiram entre si, ou seja, o fluxo do ar-condicionado não influenciou no nível de ruído dentro da cabine (Tabela 7). 
TABELA 7. Valores médios do nível de ruído para a colhedora em movimento, com mudanças na intensidade do fluxo de ar-condicionado.

\begin{tabular}{cc}
\hline Tratamentos & Ruído [(dB $(\mathrm{A})]$ \\
\hline T10 & $96,16 \mathrm{a}$ \\
T11 & $95,50 \mathrm{a}$ \\
T12 & $96,33 \mathrm{a}$ \\
\hline F calculado: 0,026 & C.V. (\%): 1,082
\end{tabular}

Médias seguidas de mesma letra nas colunas indicam que os valores apresentados não diferiram entre si, a 5\% de probabilidade.

\section{Limites de tolerância para ruído contínuo ou intermitente}

Comparando-se os resultados obtidos com o tempo de máxima exposição diária permissível (Tabela 4), nota-se que, em todos os tratamentos analisados, o tempo máximo de exposição deveria estar situado entre uma e duas horas (Tabela 8), pois além de todos se encontrarem acima de $85 \mathrm{~dB}$, constatou-se, em todas as amostragens, que os operadores não usavam protetores auriculares.

TABELA 8. Tempo de máxima exposição diária permissível, considerando-se os limites de tolerância estabelecidos pela NR 15 (MINISTÉRIO DO TRABALHO ..., 2003).

\begin{tabular}{ccc}
\hline Tratamento & Ruído $[(\mathrm{dB}(\mathrm{A})]$ & Tempo de Máxima Exposição Diária Permissível \\
\hline T1 & 95,50 & 2 horas \\
T2 & 98,80 & 1 hora e 15 minutos \\
T3 & 99,00 & 1 hora e 15 minutos \\
T4 & 99,00 & 1 hora e 15 minutos \\
T5 & 101,00 & 1 hora \\
T6 & 98,80 & 1 hora e 15 minutos \\
T7 & 96,16 & 1 hora e 15 minutos \\
T8 & 95,50 & 2 horas \\
T9 & 96,33 & 2 horas \\
T10 & 96,16 & 1 hora e 45 minutos \\
T11 & 95,50 & 2 horas \\
T12 & 96,33 & 1 hora e 45 minutos \\
\hline
\end{tabular}

\section{CONCLUSÕES}

A colhedora NH TC-57 foi a que apresentou menor nível de ruído, seguida das colhedoras SLC6200 e da MF-3640. Todas as colhedoras estudadas apresentam nível de ruído acima do limite máximo estabelecido pela norma.

\section{REFERÊNCIAS BIBLIOGRÁFICAS}

ASETE, M.G.W. Ruído e vibrações. São Paulo: FUNDACENTRO, 1983. 23 p.

ASSOCIAÇÃO BRASILEIRA DE NORMAS TÉCNICAS. Determinação do P.R.A. de tratores e máquinas agrícolas autopropelidas - Procedimento: NBR 9405. Rio de Janeiro, 1985. 2 p.

ASSOCIAÇÃO BRASILEIRA DE NORMAS TÉCNICAS. Níveis de ruído aceitáveis: NBR 10152 (NB-95). Rio de Janeiro, 1987. 4 p.

ASSOCIAÇÃO BRASILEIRA DE NORMAS TÉCNICAS. Medição do nível de ruído, no posto de operação de tratores e máquinas agrícola: NBR 9999. Rio de Janeiro, 1987. 21 p. 
ASSOCIAÇÃO BRASILEIRA DE NORMAS TÉCNICAS. Tratores agrícolas - determinação das características técnicas e desempenho: NBR 10400. Rio de Janeiro, 1988. 22 p.

BAESA, A.B.; BURK, W. Manual de medidas acústicas para el control del ruido. Barcelona, España: Blume, 1969. $176 \mathrm{p}$.

CAMPANA, C.L. Insalubridade residual por ruído em tratores cabinados. Revista Brasileira de Saúde Ocupacional, São Paulo, v.12, n.47, p.50-3, 1984.

CANÃVATE, J.O. Ergonomia, higiene e segurança nos tratores e máquinas agrícolas. In:

Máquinas y Tractores Agrícolas. Madrid: Mundi-Prensa, v.3, n.3, p.57-65, 1982.

FERNANDES, J.C.; SANTOS, J.E.G.; ANDREATTA, J.A. As fontes de ruído em tratores agrícolas. In: CONGRESSO BRASILEIRO DE ENGENHARIA AGRÍCOLA, 20., 1991, Londrina. Anais.... Londrina: Sociedade Brasileira de Engenharia Agrícola, 1991. v.2, p.1305-16.

GERGES, S.N.Y. Ruído: fenômenos e controle. Florianópolis: UFSC, 1992. 660 p.

GRANDJEAN. E. Fitting the task to the man - an ergonomic approach. London: Taylor \& Francis, 1982. $379 \mathrm{p}$.

HILBERT, J.A. Niveles de ruido en el puesto de conducción de maquinas agrícolas autopropulsadas en Argentina. Ingeniería Rural y Mecanización Agraria en el Ámbito Latinoamericano, La Plata, 1998. p.78-84.

IIDA, I. Ergonomia: projeto e produção. São Paulo: Edgard Blücher, 1990. 465 p.

INTERNATION STANDARD ORGANIZATION - ISO. Norma ISO 1999: acoustics - assessment of occupational noise exposure for hearing conservation purposes, St. Joseph, 1975. Não paginado.

INTERNATION STANDARD ORGANIZATION - ISO. Norma ISO 1999: Determination of ocupation noise expoosure and estimation of noise - induced hearing impairment, 1982. Não paginado.

MIALHE, L.G. Máquinas agrícolas: ensaios \& certificação. Piracicaba: FEALQ, 1996. 22 p. MINISTÉRIO DO TRABALHO E DO EMPREGO. Atividades e operações insalubres (115.000-6): NR15. Disponível: <http://www.mtb.gov.br/segurancaesaude/legislacao/normas/conteudo/nr15/default.asp> Acesso em 12 dezembro 2003.

PMAC. Exposição ao ruído: norma para proteção de trabalhadores que trabalham em atividades com barulho. Revista Proteção, São Paulo, v.6, n.29, p.136-8, 1994.

SILVA, R.P.; PASCHOAL, M.A.; SERON, E.; CAIXETA, R.V. Determinação do índice de mecanização agrícola de Uberaba - MG. In: CONGRESSO BRASILEIRO DE ENGENHARIA AGRÍCOLA, 27., 1998, Poços de Caldas. Anais...Lavras: Sociedade Brasileira de Engenharia Agrícola, 1998. v.3, p.220-2.

ZAMBERLAN, M.C.P.PL.; FERREIRA, D.M.P.; ALMEIDA, A.G. Avaliação ergonômica de tratores agrícolas. Rio de Janeiro: Instituto Nacional de Tecnologia, Unidade de Programas de Desenho Industrial, 1988. $138 \mathrm{p}$. 